\title{
Development and Investigation of a Miniature Copper-Acetone Loop Heat Pipe with a Flat Evaporator
}

\author{
Yury F. Maydanik, Vladimir G. Pastukhov, Mariya A. Chernysheva \\ Institute of Thermal Physics, Ural Branch of the Russian Academy of Sciences, Yekaterinburg, Russia \\ Email: maidanik@etel.ru
}

Received 28 October 2015; accepted 4 December 2015; published 7 December 2015

Copyright (C) 2015 by authors and Scientific Research Publishing Inc.

This work is licensed under the Creative Commons Attribution International License (CC BY). http://creativecommons.org/licenses/by/4.0/

(c) (i) Open Access

\begin{abstract}
The paper presents the results of development and investigation of a copper miniature loop heat pipe (LHP) with acetone as a working fluid. The device was equipped with a flat evaporator measuring $80 \times 42 \times 7 \mathrm{~mm}$ and vapor and liquid lines with an outside diameter of $3 \mathrm{~mm}$, whose lengths were $145 \mathrm{~mm}$ and $175 \mathrm{~mm}$, respectively. The LHP was tested at heat loads from $5 \mathrm{~W}$ to $60 \mathrm{~W}$, different orientations in the gravity field and heat-sink temperatures from $-40^{\circ} \mathrm{C}$ to $+50^{\circ} \mathrm{C}$. It is shown that the LHP retains its efficiency at all testing conditions. It is also mentioned that at a heat-sink temperature of $+50^{\circ} \mathrm{C}$ the device operates in the mode of constant conductivity in the whole range of heat loads, and in this case a minimum thermal resistance of the "heat source-heat sink" system equal to $0.16^{\circ} \mathrm{C} / \mathrm{W}$ is achieved, which is independent of the LHP orientation in the gravity field.
\end{abstract}

\section{Keywords}

Loop Heat Pipe, Flat Evaporator, Copper-Acetone, Different Orientation

\section{Introduction}

Loop heat pipes (LHPs) belong to passive heat-transfer devices operating on an evaporation-condensation cycle and using “a capillary mechanism” for the transportation of a working fluid [1]. The main advantages of LHPs as compared with conventional heat pipes consist in the fact that they retain a high heat-transfer capacity in transferring heat for distances up to several meters at any orientation in the gravity field, are easily configurated, provide extended possibilities for various design embodiments, may be placed in highly straitened conditions, and are also regulated quite well. In this connection, LHPs may be considered as an element of a cooling system, which ensures an almost ideal thermal link between the source and the remote heat sink, whose relative position in space 
may be any one. The most efficient is the use of these devices for heat removal from compact objects dissipating high heat fluxes such as, for example, CPU, GPU, IGBT, LED, etc.

Of particular interest are LHPs with flat evaporators, which can be well joined with heat sources that have a flat contact surface measuring up to $50 \times 50 \mathrm{~mm}$ and possess a lower thermal resistance [2]. The most widespread among such devices at present are copper LHPs with water as a working fluid, which make it possible to achieve extremely high thermal characteristics [3]-[5]. However, a practical use of copper-water LHPs, including storage and transportation, is possible only at positive ambient temperatures as the freezing of water is accompanied by its expansion and the appearance of strong deforming effects. Therefore a topical problem is the development and investigation of copper LHPs with alternative working fluids. For such working fluids one may consider, for instance, methanol and acetone, which are quite compatible with copper [6]. The choice between them depends on the priorities and concrete conditions.

As a working fluid, acetone was first used in a loop heat pipe with a cylindrical evaporator $30 \mathrm{~mm}$ in diameter made of steel and equipped with a fine-pored nickel wick [7]. An LHP about $1 \mathrm{~m}$ long was tested at both a horizontal and a vertical orientation, when the evaporator was located above the condenser. The maximum heat load in this case was, respectively, $280 \mathrm{~W}$ and $320 \mathrm{~W}$, and the temperature of the evaporator wall was equal to $52^{\circ} \mathrm{C}$ and $57^{\circ} \mathrm{C}$. Acetone as a working fluid was also used in an LHP with a cylindrical evaporator $10 \mathrm{~mm}$ in diameter of stainless steel with a nickel wick, which was tested at vibrational accelerations from $1 \mathrm{~g}$ to $12 \mathrm{~g}$ at heat loads of 15 $\mathrm{W}, 25 \mathrm{~W}$ and $70 \mathrm{~W}$ [8]. At $1 \mathrm{~g}$ the temperature of the evaporator wall at the heat loads mentioned above was, respectively, $30^{\circ} \mathrm{C}, 39^{\circ} \mathrm{C}$ and $60^{\circ} \mathrm{C}$. The same body-wick-working fluid combination was used in one more LHP equipped with a cylindrical evaporator $18 \mathrm{~mm}$ in diameter with an active-zone length of $280 \mathrm{~mm}$ [9]. The length of the vapor and liquid lines in it was $1500 \mathrm{~mm}$. The LHP was tested in a horizontal position at heat loads from $50 \mathrm{~W}$ to $300 \mathrm{~W}$. The evaporator temperature in this case varied from $52^{\circ} \mathrm{C}$ to $95^{\circ} \mathrm{C}$. Reference [10] presents the results of tests of a compact LHP made of stainless steel with a cylindrical evaporator $10 \mathrm{~mm}$ in diameter equipped with a ceramic wick. The working fluid was acetone too. The device was tested at different slopes in the range from $+90^{\circ}$ to $-90^{\circ}$ and temperatures of the water cooling the condenser from $10^{\circ} \mathrm{C}$ to $40^{\circ} \mathrm{C}$. The LHP demonstrated its serviceability at heat loads from $5 \mathrm{~W}$ to $25 \mathrm{~W}$. It was shown, in particular, that at a constant heat load of $20 \mathrm{~W}$ changes in the LHP slopes in the range mentioned resulted in changes in the temperature of the vapor line at the evaporator outlet from $66^{\circ} \mathrm{C}$ to $96^{\circ} \mathrm{C}$. As for the results of developments and investigations of copper LHPs with acetone as a working fluid, such information is absent. It can only be noted that the authors of [11] investigated the height of the capillary rise of acetone and ethanol in a copper sintered porous wick. The results have shown that the height and the speed of a capillary rise of acetone exceed considerably those of ethanol.

Besides, Reference [12] presents the results of investigating the wettability of the surface of a copper netlike wick by water, methanol and acetone. It has been noted that methanol and acetone, as distinct from water, wet the entire surface of copper, and from this viewpoint are preferable working fluids for copper heat pipes.

References [13]-[16] present the results of investigations of LHPs with working fluids that are alternatives to water, namely, acetone, ethanol, methanol and R 134. Thus, in particular, in [13] an LHP equipped with a cylindrical evaporator $12 \mathrm{~mm}$ in diameter and a wick made of PTFE demonstrated serviceability in a horizontal position in the range of heat loads from $4 \mathrm{~W}$ to $40 \mathrm{~W}$ at heat sink temperatures varying from $0^{\circ} \mathrm{C}$ to $75^{\circ} \mathrm{C}$. A minimum value of thermal resistance of $0.30 \mathrm{~K} / \mathrm{W}$ was achieved at a heat load of $30 \mathrm{~W}$ and a heat sink temperature of $75^{\circ} \mathrm{C}$.

Reference [14] presents the results of investigations of an original LHP with a flat evaporator equipped with a wick of stainless steel. Methanol was used as a working fluid. On testing the LHP a minimum thermal resistance of $0.07^{\circ} \mathrm{C} / \mathrm{W}$ is achieved at heat loads of $20-170 \mathrm{~W}$ for the boiling pool.

Reference [15] presents the results of investigations of a long-distance LHP with a cylindrical evaporator 21 $\mathrm{mm}$ in diameter with ethanol as a working fluid. A minimum thermal resistance of $0.073 \mathrm{~K} / \mathrm{W}$ was achieved at a heat load of $160 \mathrm{~W}$. The evaporator temperature in this case was equal to $81^{\circ} \mathrm{C}$.

Another paper [16] gives the results of investigations of an LHP with a flat disk-shaped evaporator equipped with a wick of stainless steel. The working fluid was methanol. Investigations were conducted at heat loads from $20 \mathrm{~W}$ to $240 \mathrm{~W}$. An LHP minimum thermal resistance of $0.26^{\circ} \mathrm{C} / \mathrm{W}$ was achieved at a maximum heat load of 240 $\mathrm{W}$, when the temperature of the evaporator wall was about $85^{\circ} \mathrm{C}$, and the heat sink temperature was equal to $0^{\circ} \mathrm{C}$.

The aim of the present work was the development and investigation of a copper LHP with a flat evaporator capable of maintaining the temperature of the object being cooled at a level that does not exceed $70^{\circ} \mathrm{C}$ at heat loads from $5 \mathrm{~W}$ to $50 \mathrm{~W}$ in a wide range of varying ambient conditions. By such conditions are meant changes in the device orientation with respect to the gravity field vector and the heat sink temperature, which affect considerably 
the LHP thermal characteristics. Methanol and acetone were considered as alternative working fluids. The choice between them was realized on the basis of a large variety of criteria.

\section{Analysis of Criteria of Choosing a Working Fluid for an LHP}

Methanol and acetone satisfy practically equally the initial criteria, such as the chemical compatibility with copper and the temperature range in which they may be used as working fluids for LHPs. As for thermophysical criteria, the choice here is not so unambiguous as for conventional heat pipes, where, as a rule, the working fluid is evaluated by the so-called quality criterion [6]:

$$
K_{l}=\frac{\rho_{l} \sigma_{l} L}{\mu_{l}}
$$

where $\rho_{l}$ is the liquid density, $\mathrm{kg} / \mathrm{m}^{3} ; \sigma_{l}$ is the surface tension coefficient, $\mathrm{N} / \mathrm{m} ; L$ is the latent heat of evaporation, $\mathrm{kJ} / \mathrm{kg} ; \mu_{l}$ is the coefficient of dynamic viscosity of the liquid, Pa·s.

This criterion makes it possible to evaluate a working fluid from the viewpoint of the maximum capacity that can be achieved in a heat pipe, where the main pressure losses take place in the capillary structure. The temperature dependence of the criterion $K_{l}$ for methanol and acetone is shown in Figure 1.

The graphs clearly point to the fact that methanol has a considerable advantage in the temperature range above $5^{\circ} \mathrm{C}$ as the value of the criterion $K_{l}$ is directly proportional to that of the maximum capacity that can be achieved at a given temperature of the working fluid. In loop heat pipes, however, the main pressure losses, as a rule, take place in the vapor phase of the working fluid during the motion in the vapor line. Therefore a more impartial assessment of a working fluid for an LHP can be obtained with the use of the criterion that may be presented as follows:

$$
K_{v}=\frac{\mu_{v}}{L \rho_{v}} \cdot \frac{\mathrm{d} T_{s}}{\mathrm{~d} P_{s}}
$$

where $\mu_{v}$ is the coefficient of dynamic viscosity of vapor, Pa.s; $L$ is the latent heat of evaporation, $\mathrm{kJ} / \mathrm{kg}$; $\rho_{v}$ is the vapor density, $\mathrm{kg} / \mathrm{m}^{3}$.

The smaller the value of this criterion, the smaller the pressure losses in the vapor phase of the working fluid. Figure 2 shows calculated values of $K_{v}$ versus the vapor temperature for methanol and acetone.

Here it is seen that at vapor temperatures lower than $30^{\circ} \mathrm{C}$ vapor pressure losses are smaller for acetone than for methanol. This is quite important because lower pressure losses make it possible for an LHP with acetone as

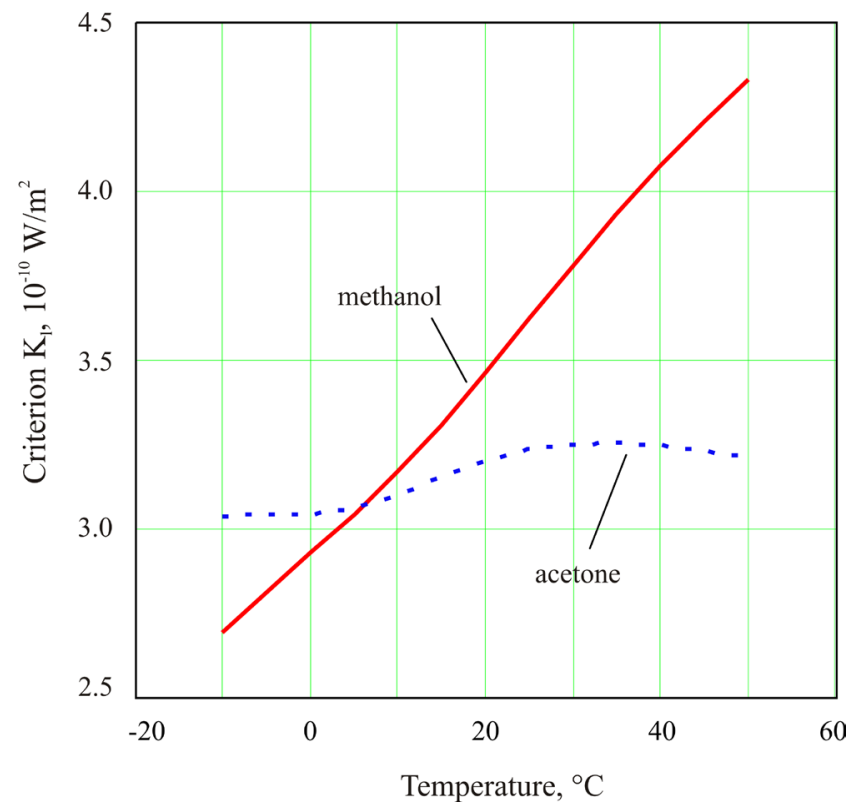

Figure 1. Criterion $K_{\mathrm{l}}$ vs. temperature. 


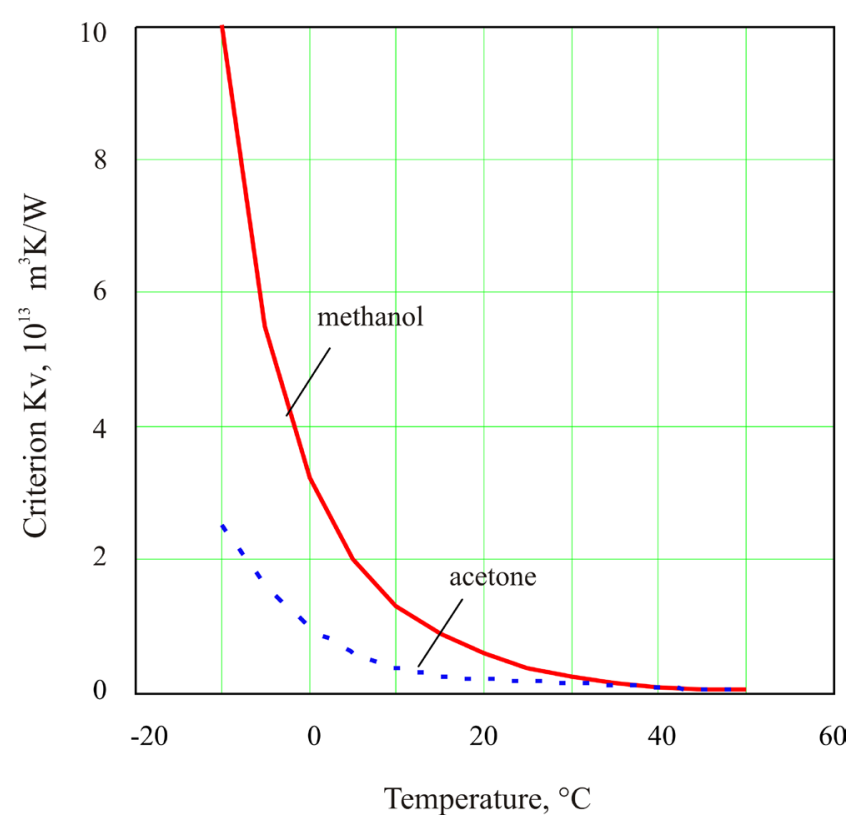

Figure 2. Criterion $K_{v}$ vs. temperature.

a working fluid to operate at a lower temperature level with respect to the temperature of the heat sink, or to decrease the diameter of the vapor line at the same temperature as that of methanol. In the latter case there appears a more favorable possibility for the configuration of lines if it is necessary to locate an LHP in straitened conditions.

There are also some other parameters that allow a more comprehensive assessment of a working fluid for an LHP. To such parameters belongs the value of $\mathrm{d} P_{s} / \mathrm{d} T_{s}$, which characterizes the slope of the saturation line of the working fluid at a given temperature $T$. This parameter is quite important for realizing one of the main conditions of the LHP serviceability [1], which may be presented as follows:

$$
\left.\Delta T \frac{\mathrm{d} P_{s}}{\mathrm{~d} T_{s}}\right|_{T}=\sum \Delta P
$$

where $\Delta T$ is the vapor temperature drop between the evaporating and the absorbing surface of the wick, ${ }^{\circ} \mathrm{C} ; \Delta P$ is the pressure losses in the loop from the evaporating surface of the wick to its absorbing surface, Pa.

The calculated value of $\mathrm{d} P_{s} / \mathrm{d} T_{s}$ for acetone and methanol is presented in Figure 3.

Here acetone has a higher value of $\mathrm{d} P_{s} / \mathrm{d} T_{s}$ in the temperature range up to $35^{\circ} \mathrm{C}$. This means that an LHP with acetone as a working fluid can be started and operate at lower temperatures as compared with the temperature of the heat sink and, consequently, have a lower thermal resistance.

An important criterion for heat pipes, including those operating in the so-called "antigravitational" regime, when the motion of the liquid phase of a working fluid proceeds against gravity forces, is "the capillary pump parameter", which is presented in the form of the relation:

$$
K_{\sigma \rho}=\frac{\sigma_{l}}{\rho_{l}}
$$

where $\sigma_{l}$ is the surface tension coefficient, $\mathrm{N} / \mathrm{m} ; \rho_{l}$ is the liquid density, $\mathrm{kg} / \mathrm{m}^{3}$.

A graphic dependence of this criterion on temperature is given in Figure 4.

It is seen that by this criterion acetone has an additional advantage over methanol, which is also confirmed by the experimental results obtained in [11].

Another factor that "plays" in favor of acetone is the vapor pressure, which does not exceed the normal ambient pressure at temperatures up to $56^{\circ} \mathrm{C}$. This allows the use of acetone in LHPs with flat evaporators, which are quite sensitive to the internal pressure, for cooling heat sources with maximum temperatures up to $60^{\circ} \mathrm{C}-70^{\circ} \mathrm{C}$, and in some cases even to $70^{\circ} \mathrm{C}-80^{\circ} \mathrm{C}$. Such a level of temperatures is quite usual, for instance, for many components of 


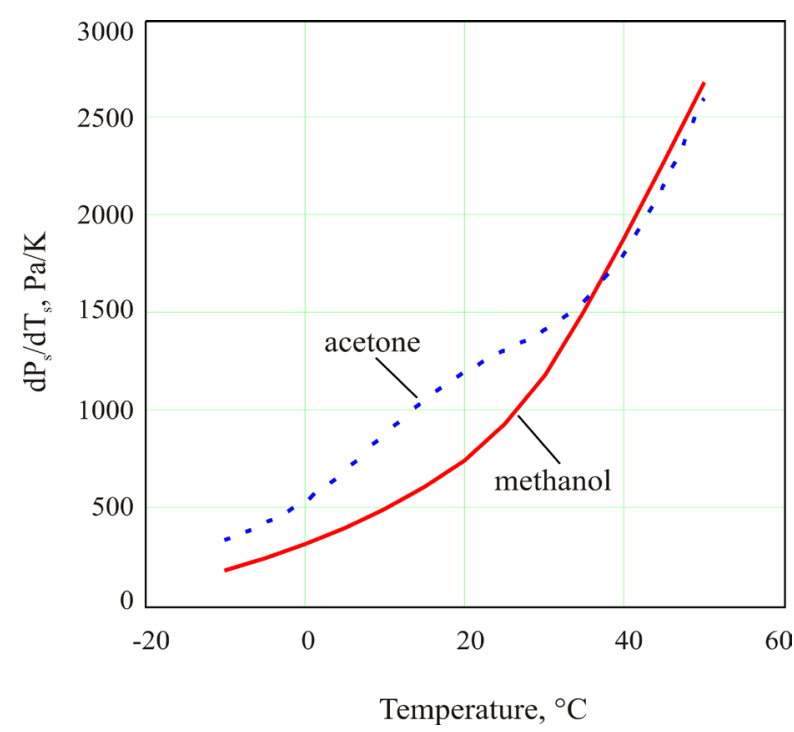

Figure 3. $\mathrm{d} P_{s} / \mathrm{d} T_{s}$ vs. temperature.

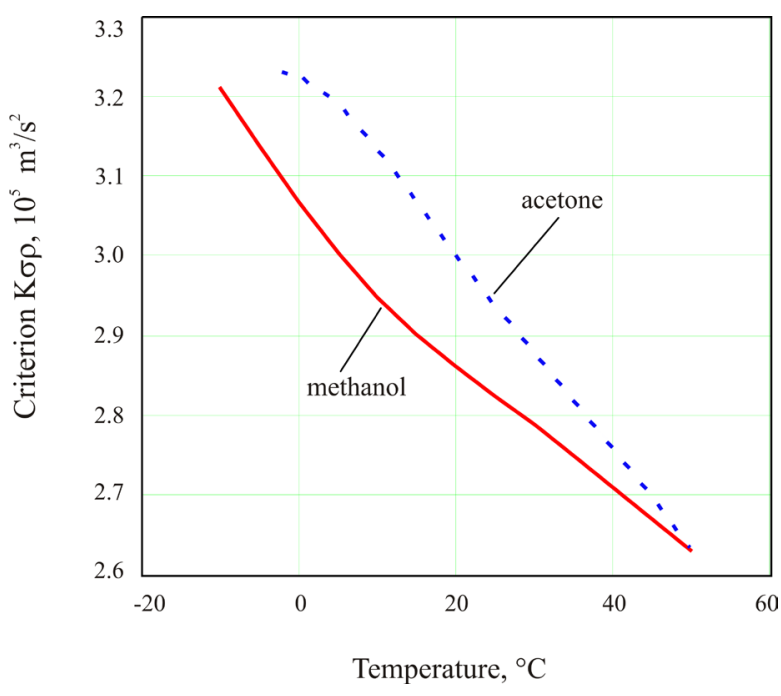

Figure 4. “Capillary pump parameter” vs. temperature.

electronics.

On the basis of the analysis presented above, the working fluid chosen was acetone.

\section{Description of an Experimental LHP}

The loop heat pipe was made of copper, including the main wick sintered from copper powder and the secondary wick in the compensation chamber made of a copper net. The evaporator had a flat shape and was equipped with a thermal interface in the form of a copper plate measuring $42 \times 42 \times 1 \mathrm{~mm}$ and corresponding to the dimensions of the heat source, which was soldered to the active zone of the evaporator. The serpentine condenser was soldered to a copper plate measuring $150 \times 40 \times 2 \mathrm{~mm}$, which served as the condenser thermal interface. The LHP scheme is shown in Figure 5. The main design parameters of the LHP are presented in Table 1.

\section{Conditions and Methods of Tests}

The LHP was tested in the range of heat loads from $5 \mathrm{~W}$ to $60 \mathrm{~W}$ at different orientations, which were characterized by the slope $\varphi$ with respect to the horizontal plane. The LHP positions are shown in Figure 6. 


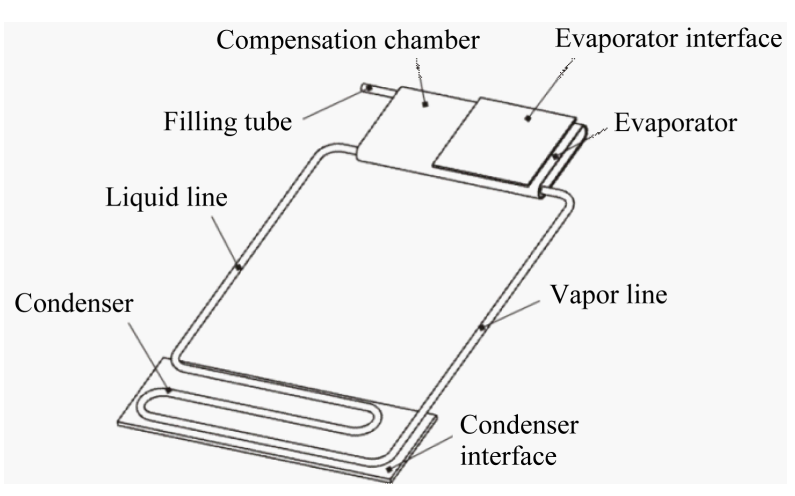

Figure 5. Scheme of an experimental LHP.
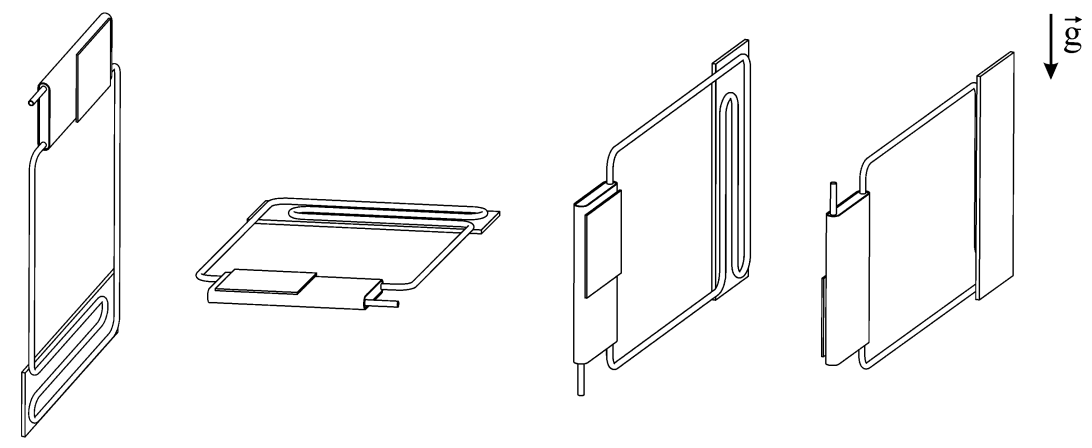

$\varphi=+90^{\circ}$

$\varphi=0^{\circ}$

$\varphi=+90^{\circ} *$

$\varphi=-90^{\circ} *$

Figure 6. LHP orientation in testing.

\section{Table 1. Main design parameters of the LHP.}

\begin{tabular}{cc}
\hline Parameter & Value \\
\hline Evaporator (length $\times$ width $\times$ thickness), mm & $80 \times 42 \times 7$ \\
Vapor line (length/diameter), mm & $145 / 3$ \\
Liquid line (length/diameter), $\mathrm{mm}$ & $175 / 3$ \\
Condenser (length/diameter), $\mathrm{mm}$ & $353 / 3$ \\
\hline
\end{tabular}

The heat source was an aluminum block with two heating cartridges located in it. The heating surface of the heat source corresponded to the dimensions of the evaporator thermal interface. The thermal interface of the condenser was pressed to a heat sink made of aluminum in the form of "a cold plate", through which a chiller pumped the liquid being thermostatted with temperatures of $-40^{\circ} \mathrm{C},-20^{\circ} \mathrm{C}, 0^{\circ} \mathrm{C}, 20^{\circ} \mathrm{C}$ and $50^{\circ} \mathrm{C}$. The block-diagram of the experimental setup is presented in Figure 7.

The heat load supplied to the heat source varied stepwise with a step of $10 \mathrm{~W}$ up to the critical values, at which the LHP temperature did not stabilize, or to the values at which the vapor temperature exceeded $60^{\circ} \mathrm{C}$. The exception was the first step from $5 \mathrm{~W}$ to $10 \mathrm{~W}$. The value of the heat load was measured by a wattmeter with an accuracy of $\pm 1 \%$. The heat losses were not taken into account. The LHP operating temperature was measured at 6 points with the help of copper-constantan thermocouples "OMEGA" T-TT-30. The readings were registered by a data acquisition unit “Agilent” 34970A (accuracy $\pm 0.1^{\circ} \mathrm{C}$ ). The main temperature reference point (TRP) was the temperature of the heat source, which was measured by a thermocouple embedded in the heating surface of the aluminum block pressed to the evaporator thermal interface with the use of a heat-conducting paste. The temperature of the thermal interface of the condenser was measured at three points distributed over its surface.

\section{Test Results}

The results of testing the LHP are given as graphic dependencies of the heat source temperature $T_{h s}$ and the 


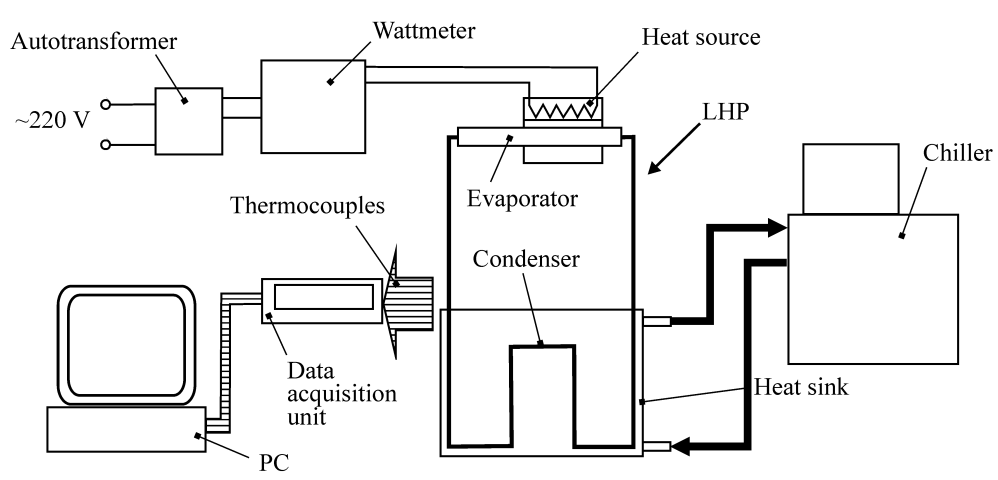

Figure 7. Block-diagram of the experimental setup.

thermal resistance of the "heat source-heat sink" system $R_{\text {sys }}$ on the heat load, slope and heat sink temperature. In this case the heat sink temperature $T_{h k}$ was determined as the average temperature of the thermal interface of the condenser. The value of $R_{\text {sys }}$ was calculated by the formula:

$$
R_{s y s}=\frac{T_{h s}-T_{h k}}{Q}
$$

where $T_{h s}$ is the heat source temperature, ${ }^{\circ} \mathrm{C} ; T_{h k}$ is the heat sink temperature, ${ }^{\circ} \mathrm{C}$; $Q$ is the heat load, W.

Figure 8 presents plots characterizing the heat load dependence of the heat source temperature at different LHP slopes for different heat sink temperatures.

These results testify that a heat load of $50 \mathrm{~W}$ was achieved in all testing conditions. It should be mentioned that the maximum heat source temperature in this case did not exceed $68^{\circ} \mathrm{C}$ even when the heat sink temperature was equal to $+50^{\circ} \mathrm{C}$. The corresponding vapor temperature was about $60^{\circ} \mathrm{C}$, which is quite acceptable for an LHP with a flat evaporator, because the internal pressure exceeded the external atmosphere pressure only slightly. The LHP also demonstrated serviceability at a negative operating temperature, which was observed at heat loads below 20 $\mathrm{W}$ when the heat sink temperature was equal to $-20^{\circ} \mathrm{C}$ and $-40^{\circ} \mathrm{C}$. A maximum heat load of $60 \mathrm{~W}$ was achieved at all slopes except $\varphi=+90^{\circ}$ when the heat sink temperature was equal to $+50^{\circ} \mathrm{C}$.

It should also be mentioned that the most interesting and unconventional results were obtained at a heat sink temperature of $+50^{\circ} \mathrm{C}$.

First, the heat load dependence of the heat source temperature has a quasi-linear character in the whole range, which points to the LHP operation in the regime of constant conductivity. This is caused by the fact that the working fluid is forced out of the condenser and fills the entire compensation chamber before the heat load supply. Thus, in the LHP operation the condensation surface does not change.

Second, it is seen that the dependence of the heat source temperature on the LHP slope is practically leveled. This fact is demonstrated more clearly in Figure 9, which presents the dependence of the heat source temperature on the heat sink temperature at different LHP slopes for heat loads of $10 \mathrm{~W}, 30 \mathrm{~W}$ and $50 \mathrm{~W}$. It is easy to see that at $T_{h k}=+50^{\circ} \mathrm{C}$ the temperatures of the heat source at all LHP slopes converge practically to one point.

Third, the thermal resistance of the "heat source-heat sink" system determined by Equation (5) reaches its minimum value of $0.16^{\circ} \mathrm{C} / \mathrm{W}$ at $T_{h k}=+50^{\circ} \mathrm{C}$, too, and depends only slightly on the LHP slope. As an example Figure 10 presents the dependence of thermal resistance on the heat sink temperature at different slopes for a heat load of $40 \mathrm{~W}$.

The characteristic heat load dependence of thermal resistance at $\varphi=+90^{\circ}$ for different heat sink temperature is presented in Figure 11. It is also seen here that at $T_{h k}=+50^{\circ} \mathrm{C}$ the thermal resistance of the system is practically independent of the heat load, which is characteristic of the LHP operation in the regime of constant conductivity.

As for the LHP operation at low heat sink temperatures of $-20^{\circ} \mathrm{C}$ and $-40^{\circ} \mathrm{C}$, here the regime of variable conductivity is observed in the whole range of heat loads for all slopes except the case where $\varphi=+90^{\circ} *$. Besides, the thermal resistance here has the highest values. This can be explained by the fact that the condensation surface at low temperatures frees itself to a considerably smaller degree than at high temperatures, and the heat rejection proceeds mainly at the expense of the increasing temperature difference between the condenser and the heat sink. Nevertheless, it should be mentioned that at low temperatures one can achieve a higher maximum heat load. 


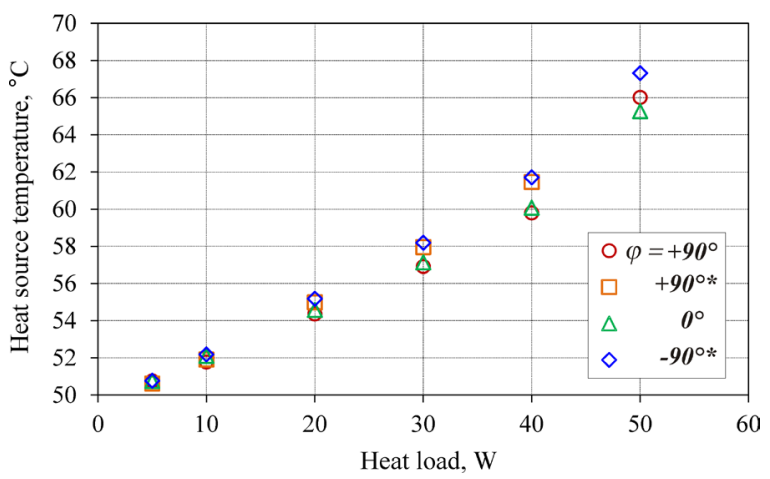

(a)

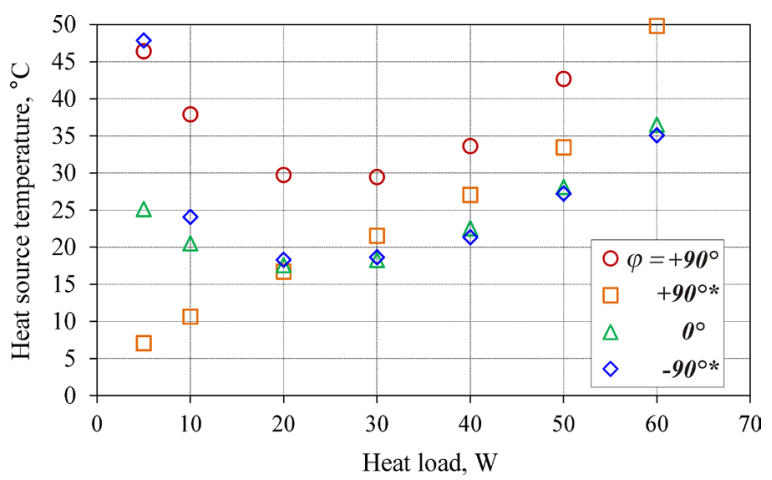

(c)

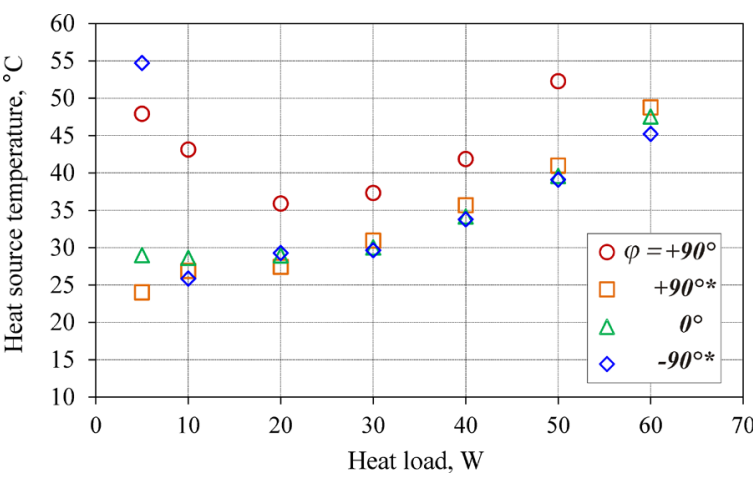

(b)

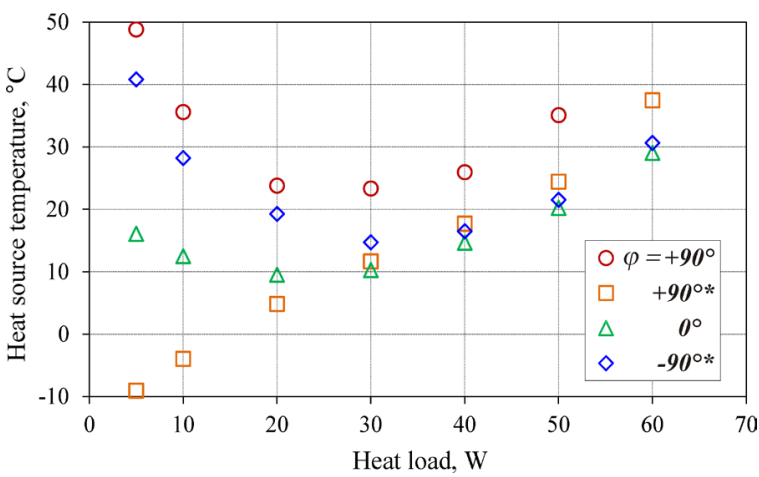

(d)

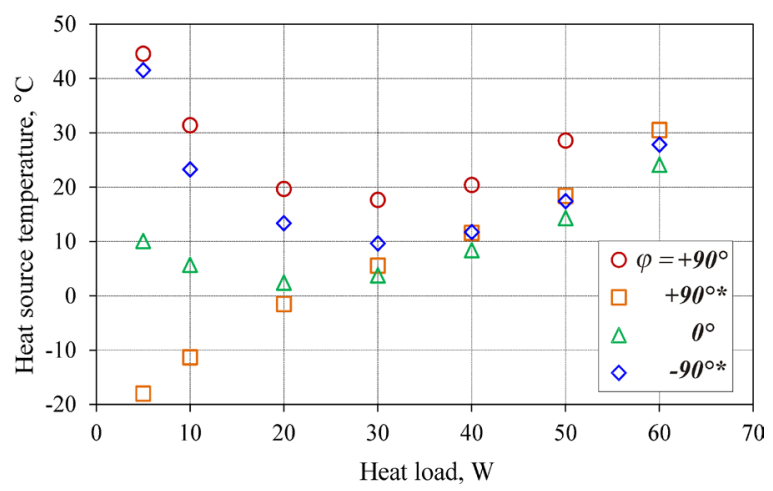

(e)

Figure 8. Dependence of the heat source temperature on the heat load at different LHP slopes at different heat sink temperatures: (a) $T_{h k}=+50^{\circ} \mathrm{C}$, (b) $T_{h k}=+20^{\circ} \mathrm{C}$, (c) $T_{h k}=0^{\circ} \mathrm{C}$, (d) $T_{h k}=-20^{\circ} \mathrm{C}$, (e) $T_{h k}=-40^{\circ} \mathrm{C}$.

Unconventional are also the LHP operating characteristics at $\varphi=+90^{\circ} *$ when the compensation chamber is located below the heating zone of the evaporator. In the graphs (Figure 8) it can be seen that the heat load dependence of the heat sink temperature is of a quasi-linear character at all values of $T_{h k}$. In accordance with this, the LHP operating regime approaches that with constant conductivity and is similar to the operation of a conventional heat pipe. This is connected with the fact that at such a position of the device the vapor line fully and the condenser partially is initially free from the liquid that fills the liquid line and, partially, the compensation chamber. Therefore an LHP start-up is not accompanied by a liquid ousting from the vapor line, and in the condenser there is already a prepared surface for vapor condensation.

It is also interesting that only at such an orientation the LHP operates at negative heat source temperatures when the temperature of the heat sink is equal to $-20^{\circ} \mathrm{C}$ and $-40^{\circ} \mathrm{C}$, and the heat load is relatively small. At all other ambient conditions the LHP operation is realized at positive heat source temperatures. 


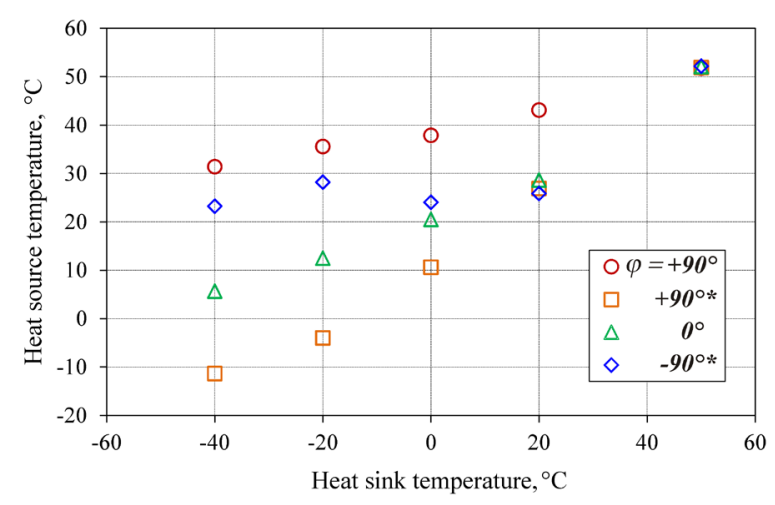

(a)

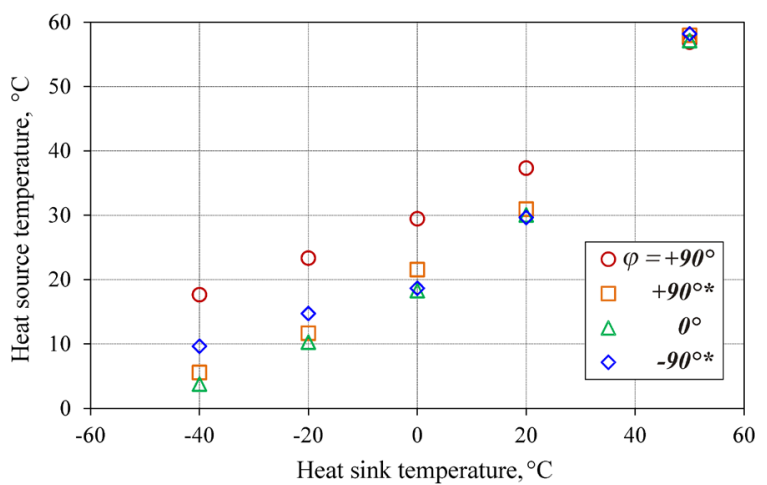

(b)

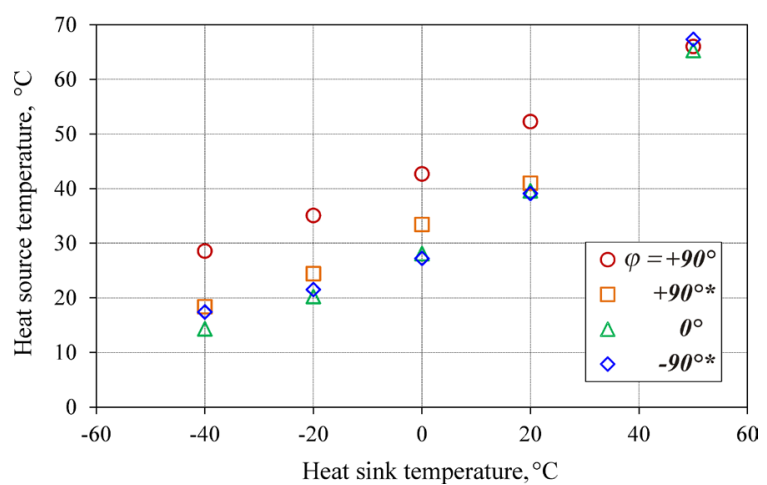

(c)

Figure 9. Dependence of the heat source temperature on the heat sink temperature at different slopes for heat loads: (a) $10 \mathrm{~W}$; (b) $30 \mathrm{~W}$; (c) $50 \mathrm{~W}$.

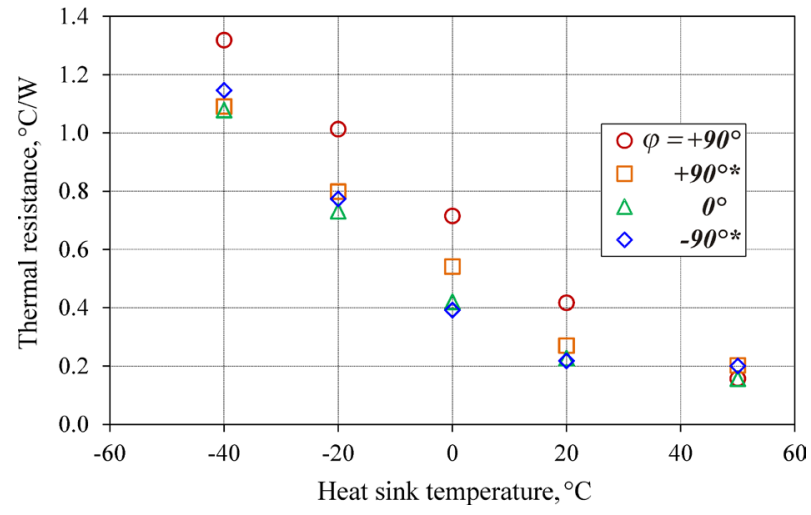

Figure 10. Dependence of thermal resistance $R_{\text {sys }}$ on the heat sink temperature at different LHP slopes and $Q=40 \mathrm{~W}$.

\section{Analysis of the Error of Thermal Resistance Measurement}

The thermal resistance was calculated by Equation (5).

The standard uncertainty of the thermal resistance can be estimated as follows:

$$
\frac{\Delta R_{s y s}}{R_{s y s}}=\sqrt{\left(\frac{\Delta T_{h s}}{T_{h s}-T_{h k}}\right)^{2}+\left(\frac{\Delta T_{h k}}{T_{h s}-T_{h k}}\right)^{2}+\left(\frac{\Delta Q}{Q}\right)^{2}}
$$

where $\Delta T_{h s}, \Delta T_{h k}$, and $\Delta Q$ are the errors of direct measurements of the temperature and the heat load.

An analysis of the accuracy of indirect measurements of the thermal resistance has shown that the maximum 


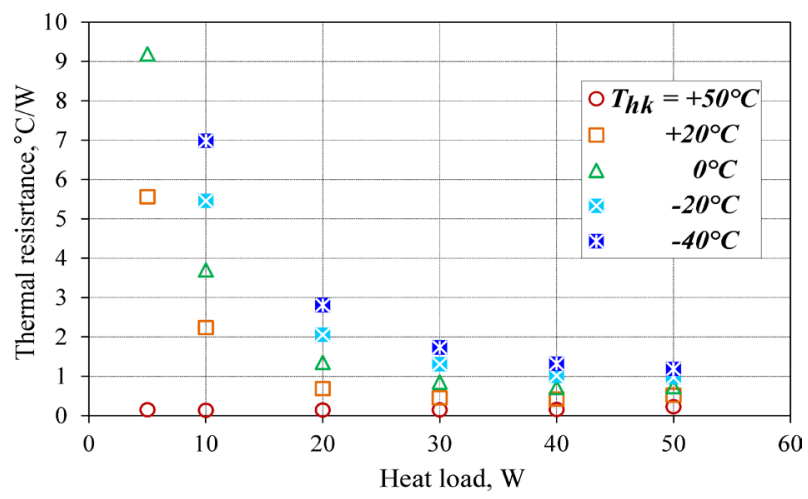

Figure 11. Dependence of the thermal resistance on the heat load at different heat sink temperatures and $\varphi=+90^{\circ}$.

Table 2. Uncertainties in the thermal resistance at $\varphi=+90^{\circ}$, different heat loads and heat sink temperatures.

\begin{tabular}{|c|c|c|c|c|c|}
\hline \multirow{2}{*}{ Heat load, W } & \multicolumn{5}{|c|}{ Uncertainties, \% } \\
\hline & $T_{h k}=-40^{\circ} \mathrm{C}$ & $-20^{\circ} \mathrm{C}$ & $0^{\circ} \mathrm{C}$ & $+20^{\circ} \mathrm{C}$ & $+50^{\circ} \mathrm{C}$ \\
\hline 5 & 12.0 & 12.0 & 12.0 & 12.0 & 39.4 \\
\hline 10 & 6.0 & 6.0 & 6.0 & 6.1 & 21.7 \\
\hline 20 & 3.0 & 3.1 & 3.2 & 3.6 & 10.3 \\
\hline 30 & 2.1 & 2.1 & 2.3 & 2.9 & 6.7 \\
\hline 40 & 1.6 & 1.7 & 1.8 & 2.3 & 4.8 \\
\hline 50 & 1.3 & 1.3 & 1.4 & 1.6 & 2.8 \\
\hline
\end{tabular}

error was observed at low values of the heat load and small values of the temperature difference $T_{h s}-T_{h k}$. Table 2 presents as an example the values of the error at $\varphi=+90^{\circ}$ for different temperatures of the liquid that cools the condenser.

It is seen that the maximum error is observed at a heat load of 5 - $10 \mathrm{~W}$ when the temperature of the cooling liquid is equal to $+50^{\circ} \mathrm{C}$. At the same time, in the rated range of heat loads from $30 \mathrm{~W}$ to $50 \mathrm{~W}$ the maximum value of the error at all conditions is in the range from $1.3 \%$ to $6.7 \%$.

\section{Conclusion}

A miniature copper loop heat pipe with a flat evaporator and acetone as a working fluid has been developed. The device has been tested in the range of heat loads from $5 \mathrm{~W}$ to $60 \mathrm{~W}$ at different orientations in the gravity field and heat sink temperatures from $-40^{\circ} \mathrm{C}$ to $+50^{\circ} \mathrm{C}$. It is shown that the LHP is capable of operating efficiently at all the conditions indicated. It has also been mentioned that even at a heat sink temperature of $+50^{\circ} \mathrm{C}$ and a maximum heat load of $50 \mathrm{~W}$ the heat source temperature does not exceed $68^{\circ} \mathrm{C}$. In this case the LHP operates in the regime of constant conductivity, the thermal resistance of the "heat source-heat sink" system reaches a minimum value at a level of $0.16^{\circ} \mathrm{C} / \mathrm{W}$ and does not depend on the LHP orientation.

\section{References}

[1] Maydanik, Yu.F. (2005) Loop Heat Pipes (Review). Applied Thermal Engineering, 25, 635-657. http://dx.doi.org/10.1016/j.applthermaleng.2004.07.010

[2] Maydanik, Yu.F., Chernysheva, M.A. and Pastukhov, V.G. (2014) Review: Loop Heat Pipes with Flat Evaporators. Applied Thermal Engineering, 67, 294-307. http://dx.doi.org/10.1016/j.applthermaleng.2014.03.041

[3] Li, J., Wang, D. and Peterson, G.P. (2010) Experimental Studies on a High Performance Compact Loop Heat Pipe with a Square Flat Evaporator. Applied Thermal Engineering, 30, 741-752. http://dx.doi.org/10.1016/j.applthermaleng.2009.12.004 
[4] Maydanik, Yu., Vershinin, S., Chernysheva, M. and Yushakova, S. (2011) Investigation of a Compact Copper-Water Loop Heat Pipe with a Flat Evaporator. Applied Thermal Engineering, 31, 3533-3541. http://dx.doi.org/10.1016/j.applthermaleng.2011.07.008

[5] Chernysheva, M.A., Yushakova, S.I. and Maydanik, Yu.F. (2014) Copper-Water Loop Heat Pipes for Energy-Efficient Cooling Systems of Supercomputers. Energy, 69, 534-542. http://dx.doi.org/10.1016/j.energy.2014.03.048

[6] Dunn, P.D. and Reay, D.A. (1976) Heat Pipes. Pergamon Press, Oxford.

[7] Gerasimov, Yu.F., Maidanik, Yu.F., Dolgirev, Yu.E., Kiseev, V.M., Filippov, G.A. and Starikov, L.G. (1976) Some Results of Investigations of Low-Temperature Heat Pipes, Working against Gravity. Journal of Engineering Physics and Thermophysics, 30, 371-375. http://dx.doi.org/10.1007/bf00867177

[8] Kiseev, V.M. (2002) Transient and Start-Up Behavior of Loop Heat Pipes Due to Gravity. Proceedings of the 12th International Heat Pipe Conference, Moscow, 19-24 May 2002, 114-119.

[9] Vasiliev, L., Lossouarn, D., Romestant, C., Alexandre, A., Bertin, Y., Piatsiushyk, Ya. and Romanenkov, V. (2009) Loop Heat Pipe for Cooling of High-Power Electronic Components. International Journal of Heat and Mass Transfer, 52, 301-308. http://dx.doi.org/10.1016/j.ijheatmasstransfer.2008.06.016

[10] Santos, P.H.D., Bazzo, E., Becker, S., Kulenovic, R. and Mertz, R. (2010) Development of LHPs with Ceramic Wick. Applied Thermal Engineering, 30, 1784-1789. http://dx.doi.org/10.1016/j.applthermaleng.2010.04.010

[11] Deng, D., Liang, D., Tang, Y., Peng, J., Han, X. and Pan, M. (2013) Evaluation of Capillary Performance of Sintered Porous Wicks for Loop Heat Pipe. Experimental Thermal and Fluid Science, 50, 1-9. http://dx.doi.org/10.1016/j.expthermflusci.2013.04.014

[12] Wong, S.-C. and Lin, Y.-C. (2011) Effect of Copper Surface Wettability on the Evaporation Performance: Tests in a Flat-Plate Heat Pipe with Visualization. International Journal of Heat and Mass Transfer, 54, 3921-3926. http://dx.doi.org/10.1016/j.ijheatmasstransfer.2011.04.033

[13] Nishikawara, M. and Nagano, H. (2014) Parametric Experiments on a Miniature Loop Heat Pipe with PTFE Wicks. International Journal of Thermal Sciences, 85, 29-39. http://dx.doi.org/10.1016/j.ijthermalsci.2014.05.016

[14] Lu, X. and Wei, J.-J. (2014) Experimental Study on a Novel Loop Heat Pipe with Both Flat Evaporator and Boiling Pool. International Journal of Heat and Mass Transfer, 79, 54-63. http://dx.doi.org/10.1016/j.ijheatmasstransfer.2014.07.089

[15] Mitomi, M. and Nagano, H. (2014) Long-Distance Loop Heat Pipe for Effective Utilization of Energy. International Journal of Heat and Mass Transfer, 77, 777-784. http://dx.doi.org/10.1016/j.ijheatmasstransfer.2014.06.001

[16] Wang, D., Liu, Z., Shen, J., Jiang, C., Chen, B., Yang, J., Tu, Z. and Liu, W. (2014) Experimental Study of the Loop Heat Pipe with a Flat Disk-Shaped Evaporator. Experimental Thermal and Fluid Science, 57, 157-164. http://dx.doi.org/10.1016/j.expthermflusci.2014.04.017 


\section{Nomenclature}

g: gravitational constant, $\mathrm{m} / \mathrm{s}^{2}$

$K$ : criterion

$L$ : latent heat of evaporation, $\mathrm{kJ} / \mathrm{kg}$

$P$ : pressure, $\mathrm{Pa}$

$Q$ : heat load, $\mathrm{W}$

$R$ : thermal resistance, ${ }^{\circ} \mathrm{C} / \mathrm{W}$

$T$ : temperature, $\mathrm{K}$

\section{Greek symbols}

$\sigma$ : surface tension coefficient, $\mathrm{N} / \mathrm{m}$

$\mu$ : coefficient of dynamic viscosity, $\mathrm{Pa} \cdot \mathrm{s}$

$\rho$ : density, $\mathrm{kg} / \mathrm{m}^{3}$

$\varphi$ : slope, grad ( $\left.{ }^{\circ}\right)$

$\Sigma$ : sum

\section{Subscripts}

hs: heat source

hk: heat sink

l: liquid

s: saturation

v: vapor 